\title{
Exploring respondents' understanding and perceptions of demographic surveillance systems in Western Africa: methodological and ethical issues
}

\author{
Nathalie Mondain \\ Department of Sociology and Anthropology \\ University of Ottawa, 55 Laurier East, Ottawa, ON, K1N 6N5 Canada \\ Phone: +1 613-562-5800, ext. 1323, Fax : +1 613-562-5906 \\ nmondain@uottawa.ca
}

Arzouma Eric Bologo

Université Catholique de Louvain, Belgique / Institut Supérieur des Sciences de la Population, Burkina Faso

Département des Sciences de la Population et du Développement (SPED)

Institut de Démographie, 1, Place Montesquieu, boîte 17

B-1348 Louvain-la-Neuve, Belgique

Phone : +32 (0)10 472951, Fax : +32 (0)10 472952

bolog_arzoum@yahoo.fr

Pascal Arduin

Institut National d'Études Démographiques (INED)

133 bd Davout, 75980 Paris cedex 20, France

Phone : +33156062058

arduin@ined.fr

\section{Abstract}

The longitudinal data collected in DSS enriched by the additional studies conducted in the same sites contribute to provide in depth insights in regarding demographic changes. However, an important issue relates to the sustainability of such systems which constrain people to repeatedly answer similar questions. This may be aggravated by the fact that populations, often uneducated and poor, do not always see the benefits of these systems and thus may provide partial answers. DSS use sophisticated methods to control for inconsistencies, but more fundamentally, it appears crucial after decades of practice to get an insight on populations' perceptions on the DSS activities and whether these make sense to them or not. Drawing from exploratory fieldworks conducted in different sites in Senegal and Burkina Faso, we examine populations' perceptions and expectations regarding the DSS activities and look for ways to open for a more participatory approach.

Keywords: Ethics; reporting back results; demographic surveillance system; communication tools; Western Africa 


\section{Résumé}

Les données longitudinales collectées dans les systèmes de suivi démographiques (DSS) enrichies par les études additionnelles conduites dans ces sites contribuent à une connaissance approfondie des changements démographiques. Toutefois, le fait que les populations soient constamment exposées à différentes enquêtes et soient contraintes de répondre à des questions similaires régulièrement, provoque leur lassitude. De plus, ces populations sont vulnérables et, ne voyant pas toujours les bénéfices de participer à de telles opérations, peuvent répondre de façon partielle. Cette situation soulève le double enjeu de la durabilité de ces systèmes et de la qualité des données. II apparaît donc essentiel après des décennies d'existence de tels systèmes en Afrique de s'attarder sur les perceptions que les populations ont des activités qui y sont menées ainsi que leurs attentes à leur égard. Tel est l'objet de l'étude comparative menée au Sénégal et au Burkina Faso dans quatre SSD décrite dans cet article.

Mots clés: Éthique, restitution, système de suivi démographique, outils de communication, Afrique de l'Ouest

\section{Introduction}

With this study we hope to contribute to the development of new ways of thinking about the research practices and ethics in demographic surveillance systems (DSS). DSS sites, depending on whether they are located in rural or urban areas, are composed of a group of villages or neighbourhoods, which have been selected on the basis of different socio-demographic criteria and whose population's demographical and epidemiological changes are followed across the years. A preliminary census of the whole population is conducted before starting the follow-up activities, and in most cases such censuses are updated on a regular basis. Longitudinal follow-ups are based on repeated visits to each household included in the site where the respondents are systematically asked the same demographic and epidemiologic questions. Typically, these visits have been occurring for years if not decades in some DSS, and, over time, the questionnaires have been further expanded with additional topics, for example education or economic items. Clearly, DSS activities presuppose a heavy and costly process that only well organized institutions can manage.

In addition to these activities, DSS sites constitute real platforms for scientific research as they also host external research teams who perform temporary surveys. As a result, these sites often become areas where populations are constantly being recruited for a variety of surveys and studies. In the past two decades, the increased weariness of populations, sometimes exasperation, has been observed by DSS staff (mainly regular interviewers) at various sites. This has led to growing concern within research teams about the efficiency and sustainability of the DSS activities they are managing. These issues are well known; however, they have yet to be subjected to systematic research. In this paper we are describing the goals and results of a comparative study of four DSS sites in Western Africa undertaken between 2006 and 
2008, which main objectives was to obtain a precise insight into the different perceptions populations have of DSS activities and identify which 'solution' could be brought to participants' weariness.

\section{Theoretical framework}

It is likely that a greater degree of participation at different levels of the research process and the involvement of the different actors, including the target populations, could contribute to solving part of this problem (Madhavan et al, 2007). One reason why people express this discontent may indeed be related to the fact that they do not fully understand the purpose of the longitudinal follow-up they have been participating to for years, and therefore, have increasingly more trouble answering questions.

One dimension of this type of participatory framework could be to report back the findings based on the DSS longitudinal data more systematically, using context sensitive communication tools that take into account local populations' social-cultural characteristics. Beyond the potential benefits for the sustainability of the DSS activities such an initiative could entail, it is likely that populations themselves would benefit in other ways. Not only would such a framework address the ethical issues related to participants' rights to information, but we also argue that, if target populations become more aware of the aims of DSS activities, as would be the case if reporting back mechanisms were put in place, they would be better able to negotiate future encounters with development workers and their institutions (Olivier de Sardan, 1995b;
Boiral et al., 1985; Lewis and Gardner, 1996, Mosse, 2005).

We thus hypothesize that, if DSS participants better understood the potential advantages of being part of such systems, their feelings of weariness and exasperation would be lessened; in addition it is likely that it would improve the quality of their answers (but this would have to be evaluated in a subsequent phase). This would require not restricting the dissemination of results to local leaders and decision makers, but also involving the target populations that participate in follow-up surveys as well as the interviewers who are in close contact with them. By adopting such a context sensitive approach, which establishes a climate of "knowledge exchange" rather than "knowledge transfer" (Gravois and Garvin, 2003), the population, through its participation in DSS activities, will acquire a better understanding of the process. Although this approach is strongly supported by most DSS research teams, in most cases, researchers have failed to systematically put reporting back activities on their agendas. One attitude, held by many researchers, being that it is not their mandate to disseminate their results directly to the targeted populations. This in turn raises the issue of the distinction between reporting back and sensitizing, which can indeed become rather fuzzy.

In order to address these issues, we designed a project with the following objectives. We would first identify the populations' perceptions in different DSS sites regarding the various survey questions/topics and, given that DSSs address several demographic, health 
and increasingly socioeconomic dimensions, which results were of interests to them. Second, we would explore the different modalities of communicating this information by taking into account the varied communication channels and spaces available within specific communities as well as local sociocultural characteristics. At the end of this phase, a strategy would be produced, identifying the main topics to be reported back and the appropriate format - mainly the communication tools to be used, where, with whom, and when in the year - in accordance with the DSS sites' socio-cultural characteristics. In this paper we report on the results of this project which has led us along some unexpected paths that may alter our initial strategy.

\section{Methodology and data}

Our project is a multisite study involving four DSSs (see Table I). We selected them based on several criteria, namely the duration of the DSS, their location, their size, the data collection process within the sites, and the managing institutions.

Table I Main characteristics in the different DSS sites

\begin{tabular}{|c|c|c|c|c|}
\hline & $\begin{array}{l}\text { Niakhar } \\
\text { (Senegal) }\end{array}$ & $\begin{array}{l}\text { Bandafassi } \\
\text { (Senegal) }\end{array}$ & $\begin{array}{l}\text { CRSN } \\
\text { (Burkina } \\
\text { Faso) }^{\mathrm{a}}\end{array}$ & $\begin{array}{l}\text { OPO } \\
\text { (Burkina Faso) }^{\text {b }}\end{array}$ \\
\hline Institution & $\begin{array}{l}\text { Institut de } \\
\text { recherche pour } \\
\text { le dévelop- } \\
\text { pement//RD } \\
\text { (France) }\end{array}$ & $\begin{array}{l}\text { Institut national } \\
\text { d'études } \\
\text { démogra- } \\
\text { phiques/INED } \\
\text { (France) }\end{array}$ & $\begin{array}{l}\text { Ministère de la } \\
\text { santé } \\
\text { (Burkina Faso) }\end{array}$ & $\begin{array}{l}\text { Institut supérieur } \\
\text { des sciences de la } \\
\text { population/ISSP } \\
\text { (Burkina Faso) }\end{array}$ \\
\hline Start $^{c}$ & 1983 & 1974 & 1992 & 2002 \\
\hline End & Cont. & 2009 & Cont. & 2008 \\
\hline $\begin{array}{l}\text { Villages/ } \\
\text { areas }\end{array}$ & 30 & 42 & $\begin{array}{l}52 \text { villages, } 7 \\
\text { sectors }\end{array}$ & 2 \\
\hline Inhabitants ${ }^{d}$ & 35000 & 11500 & 77000 & 5445 \\
\hline Ethnic group & Sereer & $\begin{array}{l}\text { Peulh, Bedik, } \\
\text { Malinké }\end{array}$ & $\begin{array}{l}\text { Marka, Bwaba, } \\
\text { Mossé, Samo, } \\
\text { Peulh }\end{array}$ & Mossé \\
\hline Religion & $\begin{array}{l}\text { Islam, Christian, } \\
\text { animist }\end{array}$ & $\begin{array}{l}\text { Islam, Christian, } \\
\text { animist }\end{array}$ & $\begin{array}{l}\text { Islam, Christian, } \\
\text { animist }\end{array}$ & $\begin{array}{l}\text { Christian } \\
\text { Islam }\end{array}$ \\
\hline $\begin{array}{l}\text { Types of } \\
\text { systematic } \\
\text { taking down }\end{array}$ & $\begin{array}{l}\text { VE, VA } \\
\text { epidemiology, } \\
\text { households, } \\
\text { education }\end{array}$ & VE, VA, HS & VE, VA, HS & $\begin{array}{l}\text { HS, VE, education, } \\
\text { housing }\end{array}$ \\
\hline Visits/year & Quarterly & Yearly & 3 times/year & Quarterly \\
\hline Interviewers & $\begin{array}{l}\text { Permanentlocal } \\
\text { interviewers }\end{array}$ & $\begin{array}{l}\text { INED } \\
\text { interviewer/ } \\
\text { local } \\
\text { interpreters }\end{array}$ & $\begin{array}{l}\text { Permanent local } \\
\text { interviewers }\end{array}$ & $\begin{array}{l}\text { Permanent local } \\
\text { interviewers }\end{array}$ \\
\hline
\end{tabular}

Note $:$ VE = vital events, $\mathrm{VA}=$ verbal autopsies, $\mathrm{HS}=$ household surveys 
a. CSRN: Centre de Recherche en Santé de Nouna

b. OPO: Observatoire de Population de Ouagadougou. This DSS was a pilot project which purpose was to assess the feasibilty of implementing a DSS at a larger scale in an urban area; the larger OPO was launched in 2008 and does not include the pilot project neighbourhoods.

c. We use the census date after which the current DSS follow-up was launched in each site.

d. Number of inhabitants at the time of our study.

\section{The methodology}

A qualitative methodology based on individual semi-structured interviews and focus group discussions conducted in two distinct phases was developed. First, the project started with an "immersion period" (Olivier de Sardan, 1995a) during which each site was visited and local key informants (local leaders, teachers, health agents, etc.) as well as inhabitants were interviewed, in most cases through group discussions. The purpose of these interviews was I) to identify the populations' perceptions of DSS activities, in particular their understanding of the demographic follow-up, and 2) to get them to assist us in identifying and prioritising which topics covered by the follow-up should be reported back. In a second step, "eclecticism phase" (Chapoulié, 2000), we wanted to evaluate people's level of information regarding the various activities going on in the DSS. We also looked for information regarding local communication channels and the spaces that could be used for reporting back procedures. We explored the most effective ways of aligning the communication of information and results with specific social-cultural contexts.

Local research assistants were hired and trained to do the fieldwork. The interviews were all conducted using the same interview guide covering the different themes listed above; information was collected through written notes which were later digitalised and analyzed. At the end of this process a report for each site was written highlighting a) the populations' understanding of the DSS research process, b) their motivation for continuing their participation despite their weariness, $c$ ) a prioritisation for the reporting back of the different topics covered by the follow-up, and finally d) the best way of communicating this information.

\section{The data}

The number of villages selected and interviews conducted are described in table 2. Due to its ethnic homogeneity, all 30 villages in the Niakhar study area were visited. In Bandafassi and Nouna, because of the ethnic diversity, we used two main criteria to select the villages in which we conducted the interviews: the number of years spent as a part of the DSS, as all villages were not included at the same time in the system and ethno-linguistic composition. It is also important to note that the Bandafassi area is unique due to its geographical remoteness and the yearly follow-up set up by the DSS managing institution.

In Ouagadougou, Wemtenga and Taabtenga are two contrasting neighbourhoods: Wemtenga is divided into plots, with urban infrastructure such as drinking water, electricity, health centers, etc. While Taabtenga is certainly not a slum, it is nonetheless composed of "spontaneous" housing and thus not 
divided into plots; it also has almost no basic urban infrastructure. Its population is poor and its education levels are low.

In each site, interviews were conducted with people who had answered the DSS follow-up questions at least once. Men and women of different age groups were identified with the assistance of the local key informants, for both individual interviews and group discussions in order to cover a diversity of perceptions depending on how long people had been involved in the DSS in their lives. Insofar as it was possible, we tried to conduct group discussions between men and women separately. However in some instances, some discussions spontaneously became mixed. This was perfectly acceptable since our research targeted issues of common interest. In many cases men were overrepresented, mainly because in the longitudinal follow up it is the head of the household, generally a man, who is interviewed. Also, the fact that we first contacted local leaders and representatives, who in most cases are men, led to a male overrepresentation.

Table 2 Total number of interviews conducted in each site

\begin{tabular}{llllllll}
\hline DSS sites & $\begin{array}{l}\text { Nb } \\
\text { villages }\end{array}$ & \multicolumn{2}{l}{$\begin{array}{l}\text { Individual } \\
\text { interviews }\end{array}$} & \multicolumn{2}{l}{ Group discussions } & \multirow{2}{*}{$\begin{array}{l}\text { Nb } \\
\text { interviews }\end{array}$} \\
\cline { 2 - 7 } & & Men & Women & Men & Women & Both n & \\
\hline Niakhar & 30 & 28 & II & 14 & 13 & 9 & 75 \\
Bandafassi* & 26 & & & 9 & 5 & 13 & 27 \\
Nouna** & 19 & 41 & 22 & 10 & 5 & 1 & 79 \\
\hline Ouagadougou & 2 & 13 & 16 & I & I & & 31 \\
\hline
\end{tabular}

Notes: in Bandafassi (*) no individual interview were conducted because with one key informant in each village collecting and reporting the information to the interviewer at his annual visit, made it less pertinent to identify participants for individual interviews as the follow-up in this particular case is more of a collective process. In Nouna (**) it is 15 villages and 4 sectors of the Nouna municipality which have been included in our study.

\section{Results}

In this section we will examine each dimension covered by our interview guide in the different sites, and, when possible illustrate our findings with quo- tations from our interview data.

The questions that embarrassed respondents or that made no sense to them

We first asked participants which questions from the follow-up questionnaires came immediately to mind. From their answers, attitudes, and reactions while responding to this question, we identified two main categories: I) questions that embarrassed or bothered them and 2) those which did not make any sense to them.

In the three rural areas, where the DSS functions as a multi-use scientific platform, many people found it difficult to distinguish between follow-up and temporary survey questions external to 
the DSS. In fact, some of the latter have left a strong impression in people's memories; especially the health oriented ones that gave rise to concrete outcomes (e.g. vaccinations, health care support, etc.).

\section{Questions not understood because they made no sense to respondents}

In the four studied DSSs, among the questions that are not understood because, to people's minds, they make no sense we find those related to population dynamics. These include questions pertaining to migrations, visits, departures, the composition of the household, the occupancy of rooms and beds, etc. Most respondents wanted an explanation of the significance for each of the topics addressed by the followup surveys. Many of them expressed surprise regarding the repetitiveness of the follow-up process, wondering: "why do you always ask the same questions?" Implicitly linked to this question is the following one: "why repeat the same question if nothing tangible ever comes of it?"

Our respondents expressed genuine weariness and exasperation with the questions from the follow-ups because they seemed irrelevant to their everyday experience. Another dimension of respondents' perceptions and their feelings which was expressed everywhere was a generalised lack of interest as the visit by the interviewer is part of a routine as the following two excerpts from a multi-ethnic Muslim village in Bandafassi highlight:

When they come, there are the greetings and then they say they have come as usual to ask questions on demography. It has become a habit (group of young men). There are no embarrassing questions but the questions surprise them because during years they come and ask you these questions. But they never say why they come. That's why some people do not want to waste their time answering them (young man).

These situations make it difficult for respondents to see the continuous battery of surveys as being meaningful and erode their interest in and their motivation for answering the questions "properly". In all areas, several respondents admitted responding quickly without really taking the time to think about the questions because there was no benefit to be had from doing so. Thus, insofar as weariness increases, the likelihood that poor quality data will be collected also increases. In the case of Taabtenga, the poorer area in Ouagadougou, it is important to note that because this area is not divided into plot, people hope that their participation in DSS activities will contribute in one way or another to improving their housing situation; when they realize it does not change anything they lose their interest in participating to the DSS: Currently in Taabtenga, inhabitants only think of issues related to plot division in their neighbourhood. All those who come and do not pay attention to this issue are not listened to and people are not much interested in what they say (a young man in Taabtenga).

\section{Embarrassing questions}

In general questions that embarrass people relate to health and respondents' economic situation. In Niakhar the embarrassing topics were mainly 
stressed by women who referred to the questions relating to fertility and health. In Bandafassi, this was also the case, especially as health issues are a common concern to all the inhabitants in the area. Because of that, they express increasing expectations of receiving some kind of health support and their disavowal and complete lack of understanding is particularly evident in the context of verbal autopsies. Because only a key informant in each village is initially asked questions dealing with populations dynamics, other villagers are only approached when a death has occurred in the household, in which case the closest relative to the dead person is asked to participate in a verbal autopsy. Therefore, people in households tend to associate the arrival of an interviewer at their homes with sad events. In effect, a number of respondents mentioned the case of women running away to avoid going through their child's death with the interviewer as these two excerpts highlight:

Some people hide in order not to respond to verbal autopsies (a young man, Muslim, focus group).

There are problems with the verbal autopsies. Questions were asked to a woman about her child's death. She refused to answer. We had to ask the health agent to convince her. She said she didn't want to remember. She finally answered but it was not her will (focus group, men, Christian).

This does not mean that mortality measurement is underestimated because of these reactions since, despite their reluctance to answer, people still participate. The point we want to make here is that in order to get them to participate, interviewers have to literally convince them to do so which may imply lower quality of data in addition to raising ethical questions about respondents' right not to answer.

In Nouna the questions that embarrass people when they think of the follow-up surveys are related to sources of income, what people use their money for, and the household's assets. These questions are those which annoy or embarrass them most as, first, in most cases respondents have to reveal this information to interviewers that come from their own geographical regions which makes them feel uncomfortable. Second, the questions relating to the household's assets reminded people of the visits of tax agents' in the past. More deeply these questions make them feel they are being asked to showcase their economic precariousness in a context where those asking the questions were in no position to offer solutions:

Imagine, your harvest is not good due to a lack of rain; you have no ox and no plough and someone comes to ask you how much you spend every day; it becomes embarrassing (an old Bwaba man in Nouna).

This was also particularly sensitive in Ouagadougou where questions relating to households' assets were very badly received including in Wemtanga, the better off area. People feel disappointed when they realize that their regular participation to the DSS does not necessarily lead to any concrete 
improvement in their situation. In that sense at the time we were interviewing them, they expressed annoyance regarding these questions:

The interviewers, who visit us every three months to talk to us, also ask us questions about what we possess in the house. They ask us if we have a television, a radio, a motorcycle, a bicycle, cattle, if the inside of the house is cemented or not. Really I must say that these questions annoy us a lot. You know, we have to give all this information without knowing what will be done with it, where it will go (a man in Wemtenga, leader of an association).

\section{Respondents' motivations to continue answering to the questions}

This situation of increasing weariness made us realize that most of our respondents felt they were insufficiently informed about the rationale behind the follow-up surveys. At the same time it raised the issue of why they continue to answer.

\section{Respondents' level of understanding of the DSS activities.}

In Niakhar and Nouna, most respondents said they had never been informed about the DSS process. In Ouagadougou, people know the topics, but do not understand the objectives, the goals or the principles of the DSS, and generally felt that they were not sufficiently informed about these aspects when the DSS was launched:

We do not understand the importance of these data. Nobody has ever explained to us the reasons why you do this work of data collection. We answer to please the interviewers. Since they need it we cannot refuse to answer. By answering we also hope that we will get something one day (Focus group, young men in Wemtenga).

An idea we encountered in the different areas was that if people had a better understanding of the purpose of DSS activities they would be in a position to provide "better" answers:

If we have explanations it will make things easier to answer. The work will be done quicker. We could give more information if we find some interest in the survey (a man in a Bedik village, catholic)

It is difficult to know to what extent participants are really not provided enough information or if they had simply failed to understand the explanations. This can be the case when researchers take for granted that the way they present their study, via simple language, is understandable. However, in all areas, interviewers and supervisors insisted that reporting back the results was perceived as essential for the community:

I think that all the inhabitants participating in the DSS need to be informed. We can see two categories of inhabitants: on the one hand there are those who want to know the objectives and the goals of the data collection; on the other hand there are those who are looking for the potential concrete effects of these activities. In brief, people want to know the objectives, the goals and the effects 
(supervisor of the Ouagadougou DSS).

When asked the question If you feel you are not sufficiently informed, why don't you ask for explanations? the answers highlighted several dimensions. First, several respondents said they had asked interviewers for explanations without, however, obtaining satisfactory answers, which suggests that the interviewers, despite the training they receive, remain not fully aware of the purposes of a demographic longitudinal follow-up. Second, reflecting the asymmetry in the power relationship vis-àvis DSS personnel, other respondents confessed that they never thought they could ask such questions. A more general attitude was to stress the 'local culture,' which dictates that visitors should be made to feel welcomed and their expectations met. In other words the person coming to interview them cannot be rejected; this raises concerns with respect to the effectiveness of standardized survey consent forms that stipulate that the interviewee can refuse to participate or stop participating when he or she feels embarrassed by the questions or the process.

Because of the research system design and the remoteness of the area, people in Bandafassi were far less informed when compared to the other sites and thus expressed less weariness with the DSS activities due to the reduced frequency of visits to households. In this sense, the geographical remoteness, the lack of modern communication networks and technologies, and the very low levels of education, are all elements that would seem to contribute to ensuring the continuity of research activities. At the same time it may also contribute to enhance power asymmetries. It is therefore essential to analyze such relationships in their respective contexts, as they may explain why people in some areas are more collaborative than in others (Boiral et al, 1985).

Reasons to continue answering the questions

In all areas, one important incentive for collaborating with researchers on the follow-up questionnaires was the expectation that their collaboration would lead to future health interventions whether these have a systematic relationship with the follow-up surveys or not. Some also claimed that they continued answering questions because they believed that one day explanations would be forthcoming.

Another key other factor in motivating people to continue to participate relates to the complex nature of the collaboration between interviewers and interviewees: they are based on power relationships insofar as the interviewer is a representative or embodiment of a powerful institution. On the other hand, interviewers, like in Niakhar and Nouna, are often "sons of the land". This situation contributes to the development of relationships based on familiarity and gratitude between interviewers and interviewees. Consequently, by participating in the interviews respondents believe that they are enabling the interviewer with his or her work; while interviewers are well positioned to convince the people to continue answering the questions. Finally, people's lack of understanding of the whole process is heightened when they see the interviewer (who is one of them) mastering the skills of reading 
and writing in their job thus contributing to increasing the interviewee's own feelings of inferiority and powerlessness: Interviewers come, they write, and they leave. We do not understand anything of all this. (a young man in a Bwaba village).

\section{The interviewers' perspectives}

Interviewers and interpreters at the different sites emphasised the strategies they had to deploy to convince participants to answer the questions, both in the case of the follow-up and the temporary surveys:

You can be face to face to a person whom you do not know and you have to ask him an embarrassing question. You have to talk in a certain way, you have to turn around. The problem in such cases is that you must not be in a hurry, people need time to think, they hesitate to ask why they are asked such questions. But interviewers are always in a hurry so they push the interpreters (one interpreter in Bandafassi).

This statement raises two crucial issues: I) the meaning which can be given to the questions asked and how the quality of the answers can be assessed in such situations; 2 ) the constraints associated with the projects with no sufficient time devoted to discussing the questionnaires and explaining the logic behind them to respondents which directly impact research practices. Interviewers told us that as long as there were health care interventions in the area, whether related to the DSS follow-up or not, their work was much easier. This was because the populations could identify concrete outcomes related to the pres- ence of the researchers in the area. When said health interventions began to diminish, interest in participating also decreased.

Interviewers felt that they too, needed more information about the DSS' research process in order to better understand what they were doing and to be able to answer respondents' worries and questions about the DSS. This is particularly the case when they interview people with some educational background (in the rural contexts it mainly refers to people who have gone through the primary school cycle). In such cases people are less cooperative, and ask more questions which interviewers or interpreters do not always know how to answer. More dialogue and negotiation is then required in order to obtain answers:

... sometimes you are stuck with people's [higher] education level, but once you are there with your question you have to deal with it, find a way out. You tell yourself: 'you got me' and finally you push the person to provide an explanation even if he does not want to (...). People have become familiar to the questions. But do they only know what demography is? (an interviewer in Niakhar).

Prominent among interviewers' daily concerns were the feeling of guilt associated with taking up people's time without being able to provide any concrete support or at the very least some type of explanation about or justification for the importance of the followup surveys:

For example, a woman was collecting water, they came to interview her; when it was finished, the 
water fountain manager had closed the tap so the woman was left without water [which meant she got into trouble when she came back to her compound]. (interviewer in Niakhar). They all admitted that the inhabitants had started to feel exploited as a consequence of having to spend so much time answering the same questions year after year. This led interviewers when describing their work to use radical expressions such as this interviewer in Niakhar:

In some compounds there can be many people (he mentions one with 200 people). It takes the whole morning, so the person whom you have "requisitioned" to answer the demographic follow-up questions has lost his morning.

Therefore, a consensus emerged in our discussions in Niakhar, but echoed by all interviewers in each site that:

The real problem is not there. They do not care for explanations. We must show with the explanations that the population is gaining something with the surveys. The populations associate the demographic survey with health surveys which have a more immediate and visible effect.

The design of the reporting back activities

In every DSS sites people favoured an interactive, interpersonal mode of reporting back the results and explaining the research process.

In the three rural areas, respondents showed a preference for meetings at the level of the neighbourhood or the village, depending on its size. In Niakhar and Nouna, men and young people insisted on the use of the local radio. In Niakhar in general, and in Nouna and Bandafassi, depending on the ethnic group, additional entertainment activities were suggested, such as traditional artistic troops playing music and singing. In general, women deemed smaller group meetings as more appropriate. The spaces people mentioned for such meetings were the village main square, religious places, or the residences of influential individuals such as the village chief's compound. The dry season was the period all respondents suggested for hosting the feedback activities as it was a period when people would be less busy. However, as most of the young adults (men and women) in Niakhar and Nouna migrate to the cities during this period it is important to plan meetings very carefully in order to reach the majority of the villagers.

In Ouagadougou respondents informed us that the best way to organise the restitution activities would be in the form of training and information workshops, forum theatres, and radio diffusion. The most adequate spaces for such meetings would be schools, areas in the vicinity of water fountains, the headquarters of associations (especially for women), and, according to young people, video clubs.

\section{Synthesis of the results and main conclusions}

Table 3 synthesizes the main results, the topics to be reported back and the design of these communication activities. However, as stated in the beginning, our research has led us to unexpected paths that we are developing below. 
Table 3 synthesis of the main results

\begin{tabular}{|c|c|c|c|c|}
\hline \multirow[t]{2}{*}{ DSS sites } & \multicolumn{2}{|c|}{ Main dimensions to report back } & \multicolumn{2}{|c|}{ How to report back } \\
\hline & Consensus & Specificities & Consensus & Specificities \\
\hline OPO & $\begin{array}{l}\text { Objectives, } \\
\text { goals of the } \\
\text { DSS } \\
\text { A strong local } \\
\text { social demand } \\
\text { for results to } \\
\text { be reported } \\
\text { back }\end{array}$ & $\begin{array}{l}\text { Health, } \\
\text { education, } \\
\text { housing; want } \\
\text { to know } \\
\text { more about } \\
\text { the leading } \\
\text { institution }\end{array}$ & $\begin{array}{l}\text { Interpersonal } \\
\text { modes of } \\
\text { communication } \\
\text { (forum theatre, } \\
\text { workshops, ...) } \\
\text { Communication } \\
\text { through media } \\
\text { (radio essentially) }\end{array}$ & $\begin{array}{l}\text { Reporting back results } \\
\text { separately in the } \\
\text { different } \\
\text { neighbourhoods } \\
\text { (information } \\
\text { workshops, debates, } \\
\text { discussions based on } \\
\text { documents such as } \\
\text { movies...) }\end{array}$ \\
\hline Nouna & $\begin{array}{l}\text { Population } \\
\text { dynamics: } \\
\text { households' } \\
\text { composition, } \\
\text { entries/exits, } \\
\text { births/deaths, } \\
\text { etc. }\end{array}$ & $\begin{array}{l}\text { Verbal } \\
\text { autopsies, } \\
\text { vital events }\end{array}$ & $\begin{array}{l}\text { In the } 3 \text { rural } \\
\text { areas there was a } \\
\text { general wish } \\
\text { expressed in } \\
\text { terms of } \\
\text { informative as } \\
\text { well as }\end{array}$ & $\begin{array}{l}\text { Depends on ethnicity } \\
\text { and religion (e.g. the } \\
\text { Bwaba insisted on the } \\
\text { entertaining dimension } \\
\text { while the Peuls } \\
\text { favoured more } \\
\text { restricted meetings) }\end{array}$ \\
\hline Niakhar & & $\begin{array}{l}\text { Punctual } \\
\text { surveys } \\
\text { (households' } \\
\text { assets, } \\
\text { nutrition...) }\end{array}$ & $\begin{array}{l}\text { entertaining; also } \\
\text { activities should } \\
\text { occur during the } \\
\text { dry season }\end{array}$ & $\begin{array}{l}\text { Older (small group } \\
\text { discussions)/younger } \\
\text { generations (bigger } \\
\text { meetings with various } \\
\text { activities) }\end{array}$ \\
\hline Bandafassi & & $\begin{array}{l}\text { Verbal } \\
\text { autopsies; } \\
\text { want to know } \\
\text { more about } \\
\text { the leading } \\
\text { institution }\end{array}$ & & $\begin{array}{l}\text { Depends on ethnicity } \\
\text { and religion (Bedik: } \\
\text { more entertainment/ } \\
\text { Peul: more restricted) }\end{array}$ \\
\hline
\end{tabular}

First, if some of the situations we identified are not necessarily specific to DSS, their particular design seems to aggravate people's negative reactions to research processes regarding two specific areas of inquiry: I) we systematically found in all sites that the 'routine' questions about population dynamics typical of the DSS follow up questionnaires did not make sense to the participants, leading them to answer casually to these questions; 2 ) the verbal autopsies were highly criticized almost everywhere; even if this type of information could be gathered in other contexts, the fact that these are part of the regu- lar follow up process and refer to sensitive dimensions of their lives increases participants' expectations in terms of actions, especially as they see the same teams asking these questions repetitively.

Hence, what is symptomatic of all DSS sites is the feeling that people are constantly being surveyed and that they do not understand why. In the end it generates a lack of interest in the process leading them to answer superficially, sometimes erroneously so as to quickly rid themselves of the interviewer. Beyond the issue of the quality of the data collected (which was not meant to 
be addressed with this project), this raises the more fundamental ethical question as to how we can disregard the population's unease and carry on with the research process. Another issue is to what extent such a situation can worsen in the future. With no systematic evaluation of interviewees' perceptions related to the DSS activities across time, it is difficult to assess whether attitudes to these activities have actually changed or not. Some respondents (in Niakhar mainly) had very positive memories of the health improvements in their community independently of who actually initiated the programs. They were therefore worried by the decrease in health care support and interventions and thus less interested in collaborating with the interviewers. Might it be that these serial follow-up surveys aimed at vulnerable populations are sustainable only insofar as individuals' vulnerability prevents them from questioning the whole research process and from refusing to continue participating?

A second point is that we should never forget that individuals are usually curious about learning as was evident among the DSS participants in the Bwa country, in Mali (Lesclingand and Hertrich, 2007). In our own project, populations are equally interested in learning about the results of the research conducted in their area. It is important to note that in Ouagadougou the populations in both neighbourhoods were already expressing a certain degree of weariness despite the fact that the pilot project had only been in place for a few years. This suggests that special care must be taken in urban areas as people appear to be more stressed by the daily constraints and are also more informed and educated even in the poorer areas. At all sites, people are keen to obtain more information in order to better understand the DSS research process. In this sense, the issue at stake goes beyond simply reporting back results; there is a pedagogic dimension highlighting the need to provide people with a deeper insight into the purposes and mechanisms of the functioning of DSSs as well as the managing institutions' mission.

Another important issue which emerged from our data is related to the power relationships amongst the main actors of the research process, i.e. the managing team, the interviewers, and the populations. These relationships appeared as key factors in explaining people's motivations to continue answering questions. In this perspective it is essential to get the insights of the local interviewers, as they establish close and regular relationships with respondents and as such, are able to sensitise researchers to the problems arising from the questionnaires and also have a better understanding of the difficulties associated with communicating with the surveyed population. In the three rural areas where interviewers and interpreters are permanently settled in the villages, people continue to answer questions which they know are not their questions. In addition, because interviewers also act as mediators between the populations and the DSS research teams, they express a strong interest in putting reporting back mechanisms in place.

Respondents' motivations for continuing to participate in the surveys are also indicative of the importance of 
their needs and of their vulnerability. They feel "trapped" by these needs to the point that they continue answering questions which not only makes no sense to them but sometimes angers them, verbal autopsies in particular, hoping that the DSS will contribute in some way to improving the conditions of their everyday life, especially with respect to health. In addition, because they face a complex process of data collection with poor levels of education and in a difficult socioeconomic situation, they often feel that they are not in a position to question the entire process. Moreover in many instances, respondents felt compelled to respond in order to help interviewers keep their jobs. These power relationships dynamics should certainly not be reproduced while reporting results back. This was clearly reflected both by the interviewers' and our respondents' suggestions regarding the best way to communicate information in their communities: a personal and interactive mode is favoured for the direct dissemination of the results to the population. Moreover, the expectation is that these meetings should be informative and entertaining. Among the communication tools that are known to combine such features and that usually succeed in stimulating interactions the following were mentioned: sketches in forum theatre activities (Stuttaford et al, 2006), commented slide shows (Lesclingand \& Hertrich, 2007), traditional music activities, broadcasting results and interviews with research leaders on the radio. In order to operationalise these activities, it is necessary to design a context-sensitive participatory model which will contribute to establishing a collaboration between the managing team, the researchers who are analyzing the data (whether part of the managing team or not), and the interviewers to ensure that the populations socio-cultural characteristics are represented.

We are fully aware that our data has several limits, among which gender bias and not systematic sampling regarding our respondents' age. Also, in this project we do not directly address the issue of the quality of the data gathered through longitudinal follow-ups, rather, we highlight the fact that it could become problematic. We insist that the particular design of DSSs aggravates the ethical and methodological challenges raised by our research practices. Hence, regarding the specific context of DSSs, it seems essential to continue working in the following directions:

I. Design more efficient and systematic ways to measure populations' weariness and also include the refusals to answer DSS questionnaires even if such reactions occur rarely as such attitudes reflect participants' discomfort;

2. Ensure that the design of reporting back activities to populations can be easily updated across years and thus perpetuated on a regular basis at the lowest cost;

3. By adopting a pedagogic comprehensive approach, ensure that both populations and interviewers understand the importance of scientific platforms such as a DSS and thus continue to participate

In this study we encouraged people to talk freely about their experience of participating in research activity (the DSS). Both interviewers and local peo- 
ple enabled us to raise fundamental questions relating to the articulation between research and action (Boiral et al, 1985; Bergier, 2000; Mesnier \& Missotte, 2003): when working with vulnerable populations, is it ethically acceptable and sustainable to continue asking the same questions year in year out via repeated visits without being able to contribute in tangible ways to the populations' well-being? Do these "concrete outcomes" need to be directly related to the research? Indeed, a salient issue with respect to demographic and epidemiological follow-ups is the gap between the long term process of the data collection process and analysis, and the short term time frame in which populations are embedded, a dimension which should never be neglected.

\section{Acknowledgments}

This work is the result of a fruitful collaboration between many different actors. We first want to thank the INDEPTH network to have funded this project. We are also grateful to the different site supervisors and managers who supported us in this work through their respective institutions: ISSP and CRSN in Burkina Faso, IRD and INED in Senegal. A special thank to Valérie Delaunay (IRD) whose precious comments and suggestions were so useful during the course of this project. Finally we address our deepest gratitude to Jose Lopez (University of Ottawa) who so kindly helped us with the translation of our paper.

\section{References}

Bergier, B., 2000. « Le versant éthique de la restitution » (chapitre 9), in : B. Bergier (ed), Repères pour une restitution des résultats de la recherche en sciences sociales ", L'Harmattan - Logiques sociales, p. 253-272

Boiral, 1985, "Logiques de recherche et logiques d'action ", in Boiral P., Lantéri J-F., Olivier de Sardan J.P., 1985, Paysans, experts et chercheurs en Afrique Noire. Sciences sociales et développement rural, Paris, Karthala

Boiral P., Lantéri J-F., Olivier de Sardan J.P., 1985, Paysans, experts et chercheurs en Afrique Noire. Sciences sociales et développement rural, Paris, Karthala

Chapoulié J-M., 2000, Le travail de terrain. L'observation des actions et des interactions, et la sociologie, in Société contemporaines.

Gardner, K. and D. Lewis, 1996, Anthropology, Development and the Post-modern Challenge, Pluto Press

Gravois Lee R. \& Theresa Garvin, 2003. «Moving from information transfer to information exchange in health and health care ", Social Science and Medicine, 56(3): 449-464.

Lesclingand M. \& V. Hertrich, 2007. Quand la population change ... une presentation des resultants de recherche au Mali, INED, Paris.

Madhavan Sangeetha, Mark Collinson, Nicholas W. Townsend, Kathleen Kahn and Stephen M. Tollman, 2007. " The implications of long term community involvement for the production and circulation of population knowledge”, Demographic Research, I7(13): 369388

Mesnier P-M.; Missotte P., 2003, La recherche-action : une autre manière 
de chercher, se former, transformer, Paris, L'Harmattan, 325 p.

Mosse, D., 2005, Cultivating

Development. An Ethnography of Aid Policy and Practice. Pluto Press.

Olivier de Sardan J.P., 1995 (a), La politique du terrain. Sur la production des données en anthropologie, in Enquête.

Olivier de Sardan, J-P., 1995 (b),
Anthropologie et développement. Essai en socio-anthropologie du changement social, APAD, Karthala

Stuttaford M., C. Bryanston, G. Lewando Hundt, M. Connor, M. Thorogood and S. Tollman, 2006. "Use of applied theatre in health research dissemination and data validation: a pilot study from South Africa”, Health, I0(I): 3I-45 